\title{
Bacterial Uropathogen among Benign Prostatic Hyperplasia Patients at a Tertiary Hospital in Nigeria
}

\author{
Adebola J. Oshodi' ${ }^{1}$, Charles Nwabuisi' ${ }^{1}$, Ademola A. Popoola ${ }^{2}$, Luke D. Edungbola ${ }^{1}$, \\ Olajide 0. Agbede1, Ajibola A. Akanbi II'1, Abayomi Fadeyi', Rasaki A. Raheem³ \\ ${ }^{1}$ Department of Medical Microbiology and Parasitology, University of Ilorin, Ilorin, Nigeria \\ ${ }^{2}$ Surgical Outpatient Department, University of Ilorin Teaching Hospital, Ilorin, Nigeria \\ ${ }^{3}$ Microbiology and Parasitology Laboratory, University of Ilorin Teaching Hospital, Ilorin, Nigeria \\ Email: ajoshodi200456@gmail.com, charlesnwabuisi2012@yahoo.com, ademola67@yahoo.com, \\ lukeduns@yahoo.com, lagbede2000@yahoo.com, aliu4567@unilorin.edu.ng, abayomifadevi@yahoo.com, \\ doubleabdul@yahoo.com
}

Received 15 February 2015; accepted 3 March 2015; published 5 March 2015

Copyright (C) 2015 by authors and Scientific Research Publishing Inc.

This work is licensed under the Creative Commons Attribution International License (CC BY). http://creativecommons.org/licenses/by/4.0/

(c) (i) Open Access

\begin{abstract}
As the lumen of the prostatic urethra becomes compromised by fibroadenomatous growth in the periurethral region of the prostate of men with Benign prostatic hyperplasia (BPH), urine outflow is obstructed progressively resulting in incomplete bladder empting causing stasis and may predispose patients to infection. Mid stream urine samples were collected from 94 BPH patients. Macroscopy, microscopy, culture and antibiotic susceptibility test were carried out on isolated uropathogens. Isolated bacteria were characterized using biochemical tests. Isolated bacterial pathogens include Proteus mirabilis, Escherichia coli, Pseudomonas aeruginosa, Klebsiella oxytoca, Morgarella morgani, K. pneumonia and Enterococcus faecalis in order of frequency. The isolates show highest resistance of $87.1 \%$ to Ciprofloxacin and least resistance of $12.9 \%$ to Imipenem. The isolates were found to be multi-drug resistant and the $12.9 \%$ resistance to Imipenem suggests presence of Carbapenemase producing bacteria among the isolates.
\end{abstract}

\section{Keywords}

Uropathogen, Benign Prostatic Hyperplasia, Urinary Tract Infection

\section{Introduction}

The urine flow from the kidneys down two narrow tubes called the Ureters. It is then stored in an organ called

How to cite this paper: Oshodi, A.J., Nwabuisi, C., Popoola, A.A., Edungbola, L.D., Agbede, O.O., Akanbi II, A.A., Fadeyi, A. and Raheem, R.A. (2015) Bacterial Uropathogen among Benign Prostatic Hyperplasia Patients at a Tertiary Hospital in Nigeria. Open Journal of Medical Microbiology, 5, 22-27. http://dx.doi.org/10.4236/ojmm.2015.51004 
the bladder and emptied through the urethra, a tube at the distal end of the bladder. The opening of the Urethra is at the distal end of the penal shaft in male and in front of the vagina in female.

Benign prostatic hyperplasia (BPH) is characterized by progressive enlargement of the prostate [1]. As the lumen of the Prostatic urethra becomes compromised by fibroadenomatous growth in the Periurethral region of the prostate, urine outflow is obstructed progressively resulting in incomplete bladder empting causing stasis and may predispose patients to infection.

Urinary tract infection (UTI) is one of the most common infection encountered by clinicians in developed and developing countries with an estimated annual global prevalence of two hundred and fifty million [2] [3]. The exact prevalence of UTI is age- and gender-related [4]. Approximately $1 \%$ of children, many of whom demonstrate functional or anatomic abnormalities of the urinary tract, develop infection during the neonatal period [5].

Females are significantly infected more than males except at the extremes of life. This is as a result of the shorter and wider urethra in females. It is estimated that $20 \%$ or more of the female population suffers some form of UTI in their lifetime. Infection in the male population remains uncommon until after the fifth decade of life, when enlargement of the prostate begins to interfere with emptying of the bladder [5] [6]. In the elderly, gynaecologic or prostatic surgery, incontinence, instrumentation, and urethral catheterization increase UTI [5].

Bacterial presence in the Urine within its tract is known as bacteriuria and can result in microbial invasion of the organs responsible for the manufacture (kidney), transport (ureters and urethra) and storage (bladder) of urine. Infection of the kidney is known as pyelonephritis. Infection of the lower urinary tract that involves the bladder is called Cystitis while it is called urethritis when the urethra is involved. UTIs occur when normal protective mechanisms fail [7]. These mechanisms include: dislodging of bacteria during urination, high urea concentration in the urine, antibacterial secretions from the prostate, high urine osmolality and white blood cells [7].

A host of pathogenic organisms can cause UTI but bacteria are the most implicated. Others include viruses, fungi and parasites. Uncomplicated UTI is usually caused by one microorganism while complicated UTI may be polymicrobial. Majority of UTI are caused by enteric bacteria that make up the normal gastrointestinal flora.

Oni et al. in their study on patients with indwelling urinary catheter, in Ibadan, Nigeria, reported that the common agents of infection to be Klebsiella sp., E. coli, Proteus sp. and Staphylococcus aureus, in order of frequency [8]. Taiwo and Aderounmu reported that in Osogbo, Nigeria Klebsiella sp. were the commonest pathogen isolated with 46 (36.6\%), followed by Pseudomonas sp. 34 (27.8\%), E. coli 26 (20.6\%), S. aureus 12 (9.5\%), P. mirabilis 4 (3.2\%), Candida albicans4 (3.2\%) and coagulate negative staphylococcus 2 (1.6\%) [9].

Getenet $e$ al. reported bacteria uropathogen at the Jimma University Specialized Hospital, Ethiopia to be $E$. coli 33.3\%, K. pneumonia 19\% and S. saprophyticus 19\% [4]. Chan et al. in Taiwan reported that of the 179 patients studied 155 were men and the most common bacteria were E. coli, P. mirabilis and Pseudomonas aeruginosa $[10]$.

Over $95 \%$ of the UTIs were caused by a single bacterium and $90 \%$ are E. coli [5]. Enterobacteriaceae (other than E. coli), Pseudomonas and Gram positive bacteria become increasingly frequent with complicated and hospitalized patients. Of the Gram positive bacteria enterococcus are the most important.

$\mathrm{BPH}$ is one of the most common causes of LUTS [11]. Men older than 50 years are at risk for clinical BPH and may have coexisting conditions mimicking BPH [11] [12]. Epidemiological studies have shown evidence of BPH in $20 \%$ of men aged $40-50$ years and $80 \%$ of men aged $70-80$ years. Additionally, $25 \%$ of men over the age of 40 have symptoms consistent with LUTS [6].

Several studies, including those of Adegoke et al. [13]; Chedi et al. [2] and Getenet \& Wondewosen [4] have been done in respect of catheterized patients. Not much has been done on uncatheterized BPH patients and Oshodi et al. [14] reported positive association between BPH and UTI.

\section{Materials and Methods}

This study was carried out at the University of Ilorin Teaching Hospital (UITH), Ilorin, Nigeria. Ethical Review Committee of the Hospital approved the study. It was a cross sectional study of urinary tract infection among benign prostatic hyperplasia (BPH) patients attending urology clinic of the surgical out-patient clinic at the UITH. Patients that were on antibiotics within the last 72 hours from time of sample collection and patients on catheter were excluded.

Sample size was calculated to be 94 using Fisher's formula $N=Z^{2} p q / d^{2}$ [15], where; $\mathrm{N}=$ the required sample size, $\mathrm{Z}=$ the confidence interval at $95 \%$ (standard value of 1.96 ), $\mathrm{p}=$ estimated prevalence of UTI associated 
with BPH put at 0.065 [16]. Using purposive sampling technique mid stream urine samples were collected from 94 BPH patients into a wide mouth, screw-capped sterile containers. Samples were processed within one hour after collection. Each Sample was mixed and divided into 2 parts.

One part was centrifuge at $2500 \mathrm{rpm}$ for 5 minutes. The supernatant poured off and the sediments tapped and poured onto a clean glass slide. Covered with a cover slip and examined under 10x and 40x objectives. Pus cells and bacterial cells were looked out for and recorded accordingly. The second part was cultured, using a standard wire loop, on CLED and Blood agar and incubated at $37^{\circ} \mathrm{C}$ for $18-24$ hours. Plates were examined for bacterial growth. Bacterial growths of $\geq 10^{5}$ colony forming units were taken to be significant. Isolates were Gram stained and necessary biochemical tests were carried out. Isolates were identified following the chart in Figure 1.

Antibiotic susceptibility tests were carried out using modified Kirbby Bauer method [3]. Gentamycin, Ceftazidime, Nitrofurantoin, Ciprofloxacin, Cefuroxine and Imipenem were tested against the isolates. Zones of inhibition diameters were interpreted as guided by Table 1 .

\section{Results}

Based on evidence of pyuria on wet preparation and significant bacteriuria on culture, 31 out of the 94 men were found to be positive for urinary tract infection giving a prevalence of 33\%, details on Table 2.

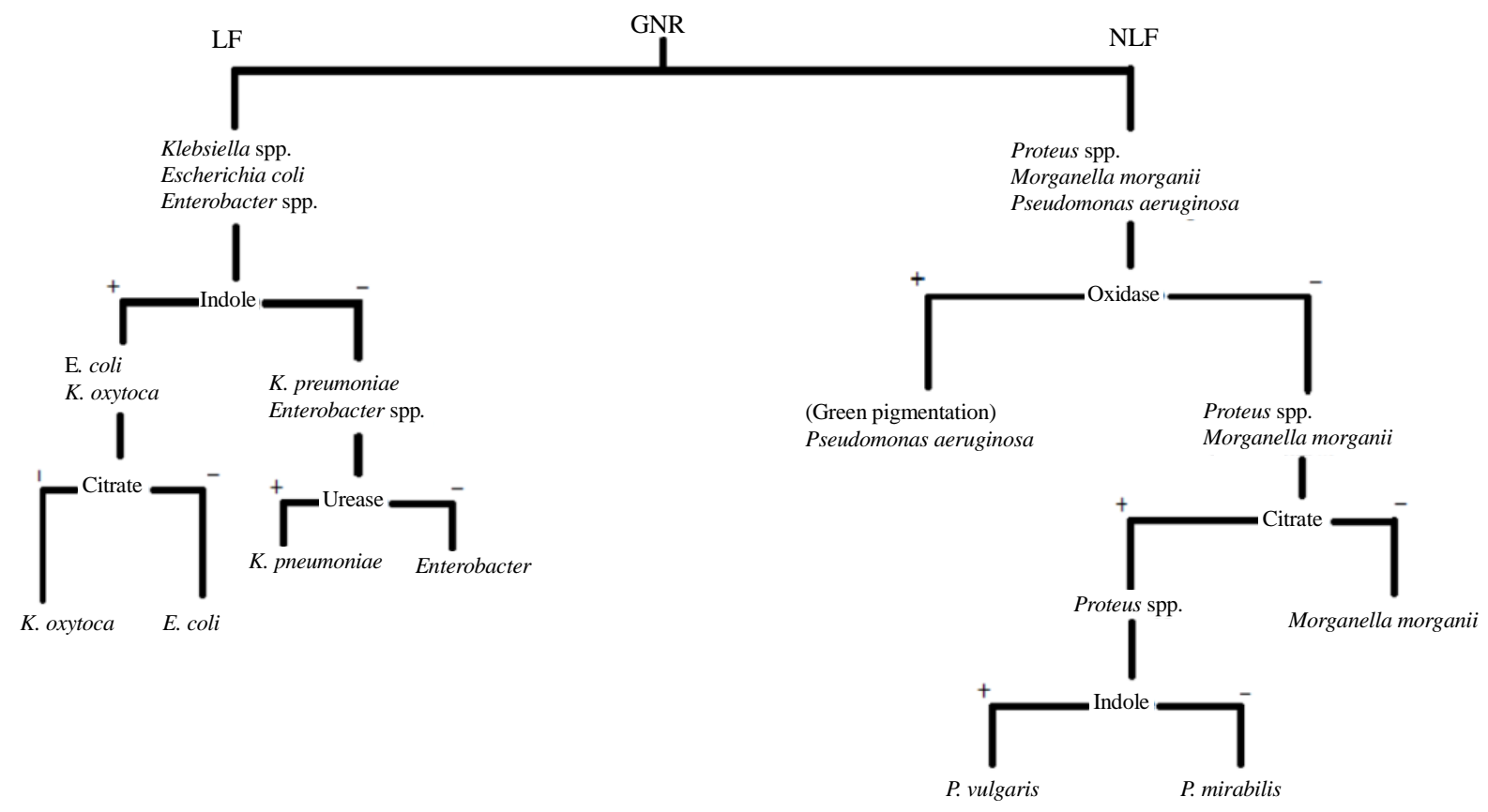

Figure 1. Flow chart of identification of gram negative rods bacterial pathogen. LF = Lactose Fermenting; NLF = Non Lactose Fermenting; GNR = Gram Negative Rod.

Table 1. Interpretation of zone of inhibition diameter for antibiotics tested.

\begin{tabular}{cccc}
\hline Antibiotics & Resistance $(\mathbf{m m})$ & Intermediate $(\mathbf{m m})$ & Susceptible $(\mathbf{m m})$ \\
\hline Gentamycin, $10 \mu \mathrm{g}$ & $\leq 12$ & $13-14$ & $\geq 15$ \\
Nitrofurantoin, $100 \mu \mathrm{g}$ & $\leq 12$ & $13-16$ & $\geq 17$ \\
Ciprofloxacin, $5 \mu \mathrm{g}$ & $\leq 15$ & $16-20$ & $\geq 21$ \\
Ceftazidime, $30 \mu \mathrm{g}$ & $\leq 14$ & $15-17$ & $\geq 23$ \\
Cefuroxime, $30 \mu \mathrm{g}$ & $\leq 14$ & $15-22$ & $\geq 23$ \\
\hline Imipenem, $25 \mu \mathrm{g}$ & $\leq 19$ & $20-22$ & \\
\hline
\end{tabular}


Proteus mirabilis is the leading cause of UTI among the subjects of the study closely followed by E. coli and Pseudomonas aeruginosa, details in Figure 2.

\section{Discussion}

There is steady increase in the prevalence of urinary tract infection with age among BPH patients, with an overall prevalence of $33 \%$ and highest prevalence of $70.6 \%$ at ages 80 years and above (Table 2) agrees with the submission of Oshodi et al. [14] that the prevalence of UTI promoted by stasis secondary to BPH should increase with age.

Table 2. Prevalence of UTI among patients diagnosed with BPH.

\begin{tabular}{ccc}
\hline Age (yrs) & n for each group & Prevalence of UTI among patients diagnosed with BPH (\%) \\
\hline $50-59$ & 17 & 11.8 \\
$60-69$ & 26 & 24.1 \\
$70-79$ & 34 & 29.4 \\
80 and above & 17 & 70.6 \\
SUMMARY & 94 & 33.0 \\
\hline
\end{tabular}

The highest prevalence was observed among ages 80 years and above while lowest prevalence was observed among ages 50 - 59 years. There is increase in prevalence with age.

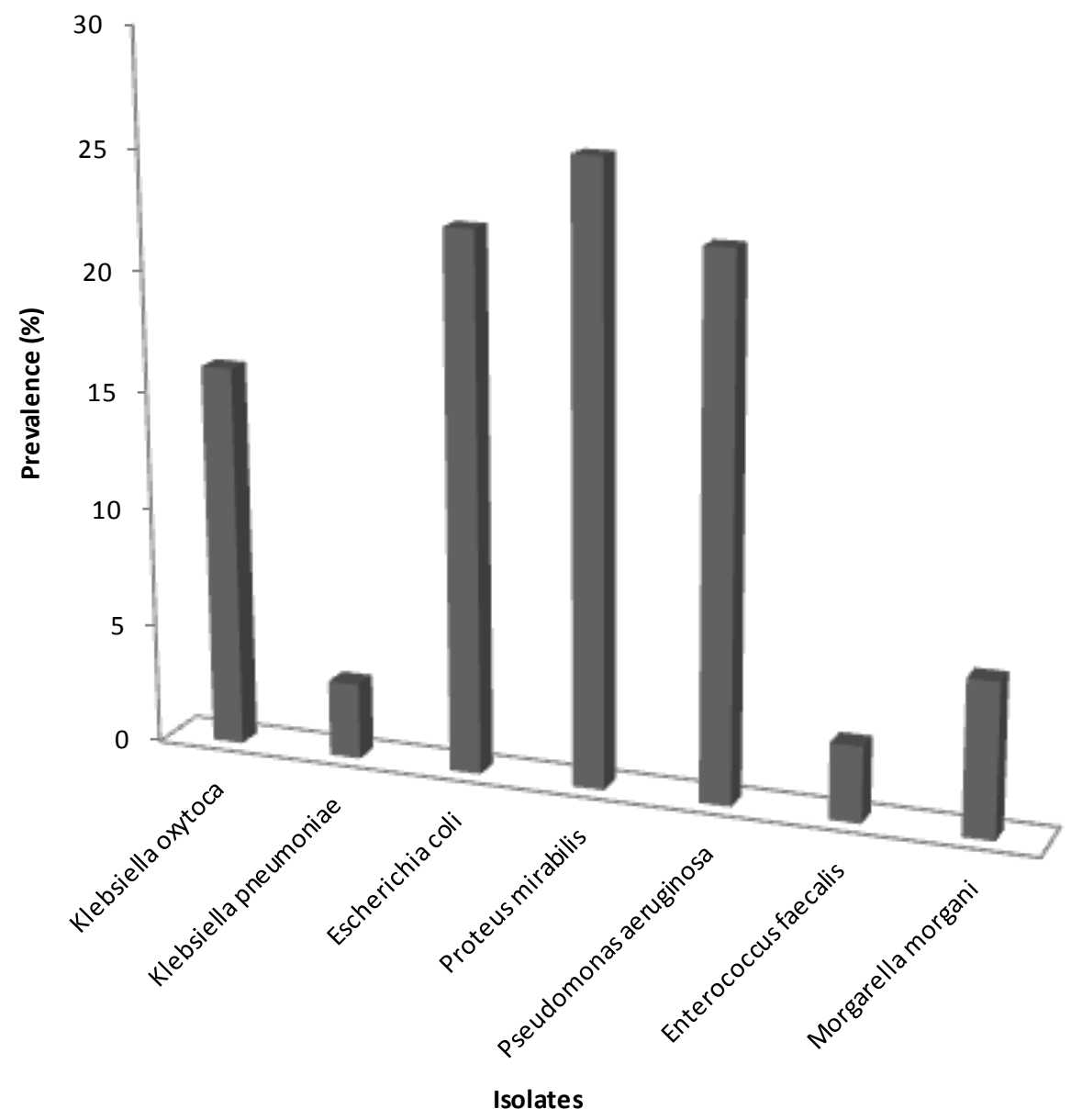

Figure 2. Prevalence of bacterial isolates among patients diagnosed with BPH and their age-matched control. 
Table 3. Summary of susceptibility pattern of bacterial isolates from patients diagnosed with BPH.

\begin{tabular}{cccc}
\hline Antibiotics & \multicolumn{3}{c}{ Isolate from patients diagnosed with BPH $(\mathbf{n}=\mathbf{3 1})$} \\
\cline { 2 - 4 } & $\mathbf{R}(\%)$ & $\mathbf{I}(\%)$ & $\mathbf{S}(\mathbf{\%})$ \\
\hline GENTAMICIN & 77.4 & 0.0 & 26.4 \\
CEFTAZIDIME & 38.7 & 22.6 & 38.7 \\
NITROFURANTION & 80.6 & 0.0 & 19.4 \\
CIPROFLOXACIN & 87.1 & 0.0 & 22.9 \\
CEFUROXIME & 71.0 & 6.5 & 67.7 \\
\hline IMIPENEM & 12.9 & 19.4 & 2.5 \\
\hline
\end{tabular}

The isolates were found to show highest resistance to Ciprofloxacin and least resistance to Imipenem, details on Table 3.

The finding that $P$. mirabilis is the leading cause of infection while $P$. aeruginosa and $E$. coli both occupied the second position is explained by the fact that host abnormality is the principal determinant of infection, with less importance to organisms factors, in complicated UTIs [17]. BPH compromises the protective mechanism of the urinary tract thereby giving the opportunistic organisms room to cause infection.

Enterobacteriaceae (other than E. coli), Pseudomonas and Gram positive bacteria became increasingly frequent with chronic, complicated and hospitalized patients of urinary disorders. Enterococci are the most important of the Gram positive [5]. This is evident in the finding of high prevalence of Proteus, Pseudomonas and E. faecalis as the only Gram positive bacteria (Figure 2).

The isolation of Morgarella morganii is in line with the submission of Auda \& Grawi [18]. This is of importance because the report of Auda \& Grawi stated that bacteriamia caused by M. morganii frequently occur secondary to UTI and with high mortality rate especially if not treated with appropriate antibiotics [18].

High resistance, to most of the antibiotics tested, shown by isolates from this study maybe due to fact that patients with BPH often experience UTI which must have led the patients to the use of different antibiotics, hence development of resistant strains. This suggests that the resistant strains undergo directional selection, in which a single phenotype is favoured, causing the trait frequency to continuously shift in one direction. The favoured trait increases in frequency independent of its relative dominance over others. In this case the favourable condition is created by the wide use of antibiotics and the favoured trait is the resistant trait.

The $12.9 \%$ resistance to Imipenem observed in this study suggests presence of Carbapenemase producing organisms at this locale.

\section{References}

[1] Chan, S.W. (2011) Pathology and Medical Therapy of Benign Prostatic Hyperplasia. The Hong Kong Medical Diary, 16, 4-7.

[2] Chedi, B.A.Z., Wannang, N.N., Halliru, M.A. and Bichi, L.A. (2009) A Seven Months Retrospective Study on Urinary Tract Infection among Patient at Aminu Kano Teaching Hospital, Kano-Nigeria. Bayero Journal of Pure and Applied Science, 2, 95-98.

[3] Forbes, B.A., Sahm, D.F. and Weissfeld, A.S. (2007) Bailey and Scott's Diagnostic Microbiology. 12th Edition, Mosby Elsevier, China, 842-855.

[4] Getenet, B. and Wondewosen, T. (2011) Bacteria Uropathogen in Urinary Tract Infection and Antibiotic Susceptibility Pattern in Jimma University Specialized Hospital, Southwest Ethiopia. Ethiopian Journal of Health Sciences, 21, 141146.

[5] Ryan, K.J. (2004) Urinary Tract Infections. In: Ryan, K.J. and Ray, C.G., Eds., Sherris Medical Microbiology an Introduction to Infectious Diseases, McGraw-Hill, New York, 867-871.

[6] Crowford, E.D. and Dall'Era, J. (2006) Benign Prostatic Hyperplasia and Progression of Lower Urinary Tract Symptom-A Review. US Genito-Urinary Disease, 44-46.

[7] Stamm, W.E. (2005) Urinary Tract Infections and Pyelonephritis. In: Kasper, D.L., Fanci, A.S., Longo, D.L., Braunwald, S.L., Hanser and Jameson, J.L., Eds., Harrison Principles of Internal Medicine, 16th Edition, McGraw Hill, New York, 1715-1721. 
[8] Oni, A.A., Mbah, G.A., Ogunkunle, M.O., Shitu, O.B. and Bakare, R.A. (2003) Nosocomial Infection: Urinary Tract Infection in Patients with Indwelling Catheter. African Journal of Clinical \& Experimental Microbiology, 4, 63-71.

[9] Taiwo, S.S. and Aderounmu, A.O.A. (2006) Catheter Associated Urinary Tract Infection: Aetiologic Agents and Antimicrobial Susceptibility Pattern in Ladoke Akintola University Teaching Hospital, Osogbo, Nigeria. African Journal of Biomedical Research, 9, 141-148.

[10] Chan, S.S., Chan, K.K., Lin, A.T., Chang, Y.H., Wu, H.H., Hsu, T.H., Chin, A.W. and Chang, L.S. (1998) Complicated Urinary Tract Infection: Analysis of 179 Patients. Zhoughua Yi Xue Za Zhi (Taipei), 61, 651-656.

[11] Barkin, J. (2011) Benign Prostatic Hyperplasia and Lower Urinary Tract Symptoms: Evidence and Approaches for Best Case Management. Canadian Journal of Urology, 18, 14-19.

[12] Lepor, H. (2004) Evaluating Men with Benign Prostatic Hyperplasia. Reviews in Urology, 6, S8-S15.

[13] Adegoke, A.O., Bamigbowu, O.E., Ayodele, M.B.O. and Blankson, C.D. (2012) Prevalence of Asymptomatic Bacteriuria in Prostatitis Subjects Attending University of Port Harcourt Teaching Hospital. African Journal of Microbiology Research, 6, 4443-4448.

[14] Oshodi, A.J., Nwabuisi, C., Popoola, A.A., Edungbola, L.D., Agbede, O.O., Akanbi II, A.A., Fadeyi, A., Nyanmgee, A., Adeyemi, O. and Raheem, R.A. (2014) Association between Benign Prostatic Hyperplasia and Urinary Tract Infection. Continental Journal of Biomedical Sciences, 8, 7-11.

[15] Gichobi, D., Wanzala, P., Mutai, J. and Kamweya, A. (2010) Factors Associated with Disease Outcome in Children at Kenyatta National Hospital. Journal of Public Health and Epidemiology, 2, 262-266.

[16] Hurst, F.P., Neff, R.T., Falta, E.M., Jindal, R.M., Lentine, K.L., Swanson, J.S., Agodoa, L.Y. and Abbott, K.C. (2009) Incidence, Predictors, and Associated Outcomes of Prostatism after Kidney Transplantation. Clinical Journal of the American Society of Nephrology, 4, 329-336. http://dx.doi.org/10.2215/CJN.04370808

[17] Nicolle, L.E. (2005) Complicated Urinary Tract Infection in Adults. Canadian Journal of Infectious Diseases \& Medical Microbiology, 16, 349-360.

[18] Auda, J.G. and Al-Grawi, I.G. (2009) Isolation, Identification and Antimicrobial Susceptibility of Uropathogenic Morganella morganii. Al-Kindy College Medical Journal, 5, 32-35. 